\title{
Hypoxia Alters the Subcellular Distribution of Protein Kinase C Isoforms in Neonatal Rat Ventricular Myocytes
}

\author{
Michelle Goldberg, ${ }^{\S}$ Hong Lu Zhang, ${ }^{\ddagger}$ and Susan F. Steinberg ${ }^{\star \ddagger}$ \\ *Department of Medicine, ${ }^{\ddagger}$ Department of Pharmacology, and ${ }^{\S}$ Department of Pediatrics, Columbia University, New York 10032
}

\begin{abstract}
Cardiac myocytes coexpress multiple protein kinase $\mathrm{C}$ (PKC) isoforms which likely play distinct roles in signaling pathways leading to changes in contractility, hypertrophy, and ischemic preconditioning. Although PKC has been reported to be activated during myocardial ischemia, the effect of ischemia/hypoxia on individual PKC isoforms has not been determined. This study examines the effect of hypoxia on the subcellular distribution of individual PKC isoforms in cultured neonatal rat ventricular myocytes. Hypoxia induces the redistribution of PKC $\alpha$ and PKC $\epsilon$ from the soluble to the particulate compartment. This effect (which is presumed to represent activation of PKC $\alpha$ and PKC $\epsilon$ ) is detectable by $1 \mathrm{~h}$, sustained for up to $24 \mathrm{~h}$, and reversible within $1 \mathrm{~h}$ of reoxygenation. Inhibition of phospholipase $C$ with tricyclodecan-9-yl-xanthogenate (D609) prevents the hypoxia-induced redistribution of $\mathrm{PKC} \alpha$ and PKC $\epsilon$, whereas chelation of intracellular calcium with 1,2-bis(2aminophenoxy)ethane- $N, N, N^{\prime}, N^{\prime}$-tetraacetic acid (BAPTA) blocks the redistribution of $\mathrm{PKC} \alpha$, but not $\mathrm{PKC} \epsilon$; D609 and BAPTA do not influence the partitioning of PKC $\alpha$ and PKC $\epsilon$ in normoxic myocytes. Hypoxia, in contrast, decreases the membrane association of $\mathrm{PKC} \delta$ via a mechanism that is distinct from the hypoxia-induced translocation/activation of $\mathrm{PKC} \alpha / \mathrm{PKC} \epsilon$, since the response is slower in onset, slowly reversible upon reoxygenation, and not blocked by D609 or BAPTA. The hypoxia-induced shift of PKC $\delta$ to the soluble compartment does not prevent subsequent 4- $\beta$ phorbol 12-myristate-13-acetate-dependent translocation/activation of PKC $\delta$. Hypoxia does not alter the abundance of any PKC isoform nor does it alter the subcellular distribution of PKC $\lambda$. The selective hypoxia-induced activation of $\mathrm{PKC}$ isoforms through a pathway involving phospholipase $\mathrm{C}(\mathrm{PKC} \alpha / \mathrm{PKC} \epsilon)$ and intracellular calcium $(\mathrm{PKC} \alpha)$ may critically influence cardiac myocyte contractility, gene expression, and/or tolerance to ischemia. (J. Clin. Invest. 1997. 99:55-61.) Key words: protein kinase C • hypoxia $\bullet$ cardiac myocytes
\end{abstract}

Address correspondence to Susan F. Steinberg, Associate Professor of Pharmacology and Medicine, Department of Pharmacology, Columbia University, College of Physicians and Surgeons, 630 West 168th Street, New York, NY 10032. Phone: 212-305-4297; FAX: 212305-8780; E-mail: STEINBS@CUDEPT.CIS.Columbia.edu

Received for publication 4 June 1996 and accepted in revised form 22 October 1996.

J. Clin. Invest.

(C) The American Society for Clinical Investigation, Inc.

0021-9738/97/01/0055/07 \$2.00

Volume 99, Number 1, January 1997, 55-61

\section{Introduction}

Protein kinase $\mathrm{C}(\mathrm{PKC})^{1}$ is an important component of the signal transduction pathway used by cells to respond to a variety of extracellular stimuli (1). PKC has been implicated in the regulation of contractile function, gene expression, and/or tolerance to ischemia in cardiac tissue (2). However, the precise identity of the PKC species that mediate these functions remains uncertain, since several PKC isoforms are coexpressed by cardiac myocytes. For example, neonatal rat ventricular myocytes express at least one conventional PKC isoform $(\mathrm{PKC} \alpha)$ which is activated by calcium, phosphatidylserine, and diacylglycerol (DAG)/phorbol esters, two novel PKC isoforms (PKC $\delta$ and $\mathrm{PKC} \epsilon$ ) which are activated by phosphatidylserine and DAG/phorbol esters (but do not require calcium for maximal enzyme activation), and one atypical PKC isoform (recently identified as $\mathrm{PKC} \lambda$, rather than PKC $\zeta$ [3]) which is activated by phosphatidylserine (but not by calcium or DAG/ phorbol esters [4-9]). Apart from differences in their cofactor requirements for enzymatic activation, these $\mathrm{PKC}$ isoforms target to distinct subcellular loci (including the perinuclear membrane, cytoskeleton, and myofibrillar apparatus [6]) and are presumed to differ in their in vivo substrate specificity.

There is growing evidence that individual components of the phosphoinositol lipid signaling pathway that result in $\mathrm{PKC}$ activation can be influenced by hypoxia/ischemia and/or reperfusion. For example, ischemic and/or hypoxic insults have been reported to lead to increased $\alpha_{1}$-adrenergic receptor density in cat, dog, guinea pig, and rat myocardium (10-14). In the ischemic canine myocardium, the increase in $\alpha_{1}$-adrenergic receptor density is associated with enhanced inositol trisphosphate $\left(\mathrm{IP}_{3}\right)$ accumulation (15). Hypoxia also enhances receptordependent phosphoinositide hydrolysis in cultured neonatal rat ventricular myocytes (16). However, in this system, the effects of hypoxia are confined to components of the signaling pathway distal to the receptor, since hypoxia does not detectably alter $\alpha_{1}$-receptor density $(16,17)$. While perturbations that lead to increased inositol phosphate accumulation are anticipated to be associated with enhanced DAG formation, which would stimulate PKC, to the best of our knowledge the effects of hypoxia on DAG have not been described. Nevertheless, there is recent evidence that ischemia induces the translocation of PKC enzyme activity from the soluble to the particulate fraction of rat ventricular myocardial tissue via an $\alpha_{1}$-receptor-independent pathway (18). While this is presumed to represent ischemia-induced activation of $\mathrm{PKC}$, there is a paucity of information on the effects of ischemia/hypoxia on individual PKC isoforms (19). Accordingly, the goal of the

1. Abbreviations used in this paper: BAPTA, 1,2-bis(2-aminophenoxy)ethane- $N, N, N^{\prime}, N^{\prime}$-tetraacetic acid; D609, tricyclodecan-9-yl-xomthogenate; DAG, diacylglycerol; $\mathrm{IP}_{3}$, inositol triphosphate; $\mathrm{PKC}$, protein kinase $\mathrm{C}$. 
present study was to determine whether the hypoxic component of an ischemic insult modulates individual PKC isoforms and explore the mechanism(s) underlying this phenomenon.

\section{Methods}

Preparation of cultured neonatal rat ventricular myocytes. Cardiac myocytes were isolated from the ventricles of 2-d-old Wistar rats by a trypsin dispersion procedure and were plated at a density of $0.5 \times 10^{6}$ cells $/ \mathrm{ml}(10 \mathrm{ml} / \mathrm{dish})$ onto $100-\mathrm{mm}$ culture dishes and cultured in MEM containing $5 \times 10^{-6} \mathrm{M}$ hypoxanthine and $12 \mathrm{mM} \mathrm{NaHCO}_{3}$ supplemented with $10 \%$ fetal calf serum according to a protocol described previously (20). Although the culture technique includes a preplating step that effectively decreases fibroblast contamination, it is well known that small numbers of cells with proliferative capability such as cardiac fibroblasts persist in the myocardial cell cultures. Proliferation of these cells was further curtailed with an irradiation protocol (21).

The cultures were exposed to chronic hypoxia as described previously with one minor modification (16). The previous study used an anaerobic chamber that was designed to rapidly consume $\mathrm{O}_{2}$ and thereby maintain minimal oxygen levels. This study used a modified version of that chamber which affords more flexibility in its control of the gas environment. The chamber is an airtight vinyl glove box equipped with an automated oxygen controller; the oxygen controller continuously senses oxygen and regulates an automated valve system which regulates gas inflow and functions to maintain a preset atmospheric oxygen level (Coy Lab Products, Grass Lake, MI). In all other respects, chamber design is similar to that previously used. Cultures enter the hypoxia chamber through an airlock transit chamber that is purged with a $\mathrm{CO}_{2} / \mathrm{N}_{2}$ gas mixture to reestablish an hypoxic atmosphere. In this fashion, cultures are subjected to the preset hypoxic environment immediately upon entry into the chamber. Within the hypoxia chamber, cells are maintained in a humidified atmosphere at $37^{\circ} \mathrm{C}$. Experiments are carried out to completion in the apparatus, without reexposure to ambient air.

Experimental protocols were initiated by placing cultures, $4 \mathrm{~d}$ after isolation, into the hypoxia chamber (set to $1.2 \% \mathrm{O}_{2}$, with $5 \% \mathrm{CO}_{2}$ and the balance $\mathrm{N}_{2}$ ) or a standard cell culture incubator maintained at normal atmospheric $\mathrm{O}_{2}$ (with $5 \% \mathrm{CO}_{2}$ ). In preliminary experiments, we demonstrated that the $\mathrm{pO}_{2}$ of the culture medium drops to $\sim 45$ $\mathrm{mmHg}$ at $30 \mathrm{~min}, \sim 20 \mathrm{mmHg}$ at $1 \mathrm{~h}$, and then stabilizes at this level thereafter. The cultures tolerate the hypoxic environment well. We previously reported that there is no detectable evidence of cell death, based on Trypan blue exclusion or intracellular lactate dehydrogenase release (16). Further evidence that the hypoxic stress used in this study is not associated with any significant metabolic, structural, or functional damage to the cells comes from the observation that the myocytes continue to beat for up to 6- $8 \mathrm{~h}$ in the hypoxia chamber; although spontaneous contractile activity tends to cease with longer intervals in the hypoxia chamber, it resumes promptly (within 1-2 min) upon reexposure to ambient atmosphere and grossly remains stable for the ensuing $24 \mathrm{~h}$.

Protein extraction. The subcellular distribution of PKC isoforms in cell fractions was determined as described previously with minor modifications (4). Briefly, ventricular myocyte cultures were washed with phosphate buffered saline and then immediately lysed in $0.4 \mathrm{ml}$ ice-cold homogenization buffer $(20 \mathrm{mM}$ Tris- $\mathrm{HCl}, \mathrm{pH} 7.5,2 \mathrm{mM}$ EDTA, $2 \mathrm{mM}$ EGTA, $6 \mathrm{mM} \beta$-mercaptoethanol, $50 \mu \mathrm{g} / \mathrm{ml}$ aprotinin, $48 \mu \mathrm{g} / \mathrm{ml}$ leupeptin, $5 \mu \mathrm{M}$ pepstatin A, $1 \mathrm{mM}$ phenylmethylsulfonyl fluoride, $0.1 \mathrm{mM}$ sodium vanadate, and $50 \mathrm{mM} \mathrm{NaF}$ ), sonicated, and centrifuged at 100,000 $\mathrm{g}$ for $1 \mathrm{~h}$. The supernatant was removed (soluble fraction) and the pellet was resuspended in $0.2 \mathrm{ml}$ homogenization buffer containing $1 \%$ Triton $\mathrm{X}-100$ to solubilize particulate proteins. After shaking on ice for $30 \mathrm{~min}$, Triton X-100 insoluble proteins were removed by centrifugation at $10,000 \mathrm{~g}$ for $10 \mathrm{~min}$, and the supernatant (which contains virtually all of the membrane associated PKC isoforms, but only $\sim$ two thirds of the original cell pellet protein) was saved (particulate fraction). It is important to note that total protein recovery from normoxic and hypoxic cultures was identical $(983 \pm 80$ and $807 \pm 84 \mu \mathrm{g} / \mathrm{dish}$, respectively; $n=14$, NS). Moreover, the partitioning of protein to the soluble and particulate fraction was identical in normoxic and hypoxic cultures (i.e., the soluble fraction constituted $22.1 \pm 1.7$ and $24.3 \pm 2.7 \%$ of total cell protein and the Triton X-100 soluble particulate fraction constituted $49.2 \pm 3.4$ and $52.4 \pm 5.8 \%$ of total cell protein in normoxic and hypoxic cultures, respectively, NS).

Immunoblot analysis. Samples were electrophoresed on an $8 \%$ SDS-polyacrylamide gel and transferred to nitrocellulose. Prestained molecular weight markers were electrophoresed in parallel. After an incubation in $5 \%$ dry milk, $50 \mathrm{mM}$ Tris, $\mathrm{pH} 7.5,200 \mathrm{mM} \mathrm{NaCl}$, and $0.1 \%$ Triton-X 100 , (blocking buffer $\mathrm{I}$ ) for $1 \mathrm{~h}$ at room temperature to block nonspecific binding, the nitrocellulose was probed with primary PKC isoform specific antisera. The four PKC isoform-specific antisera used in this study include a monoclonal anti-PKC $\alpha$ antibody and three polyclonal antisera generated against synthetic peptides corresponding to the carboxyl-terminal variable regions of PKCס, PKC $\epsilon$, and PKC $\zeta$. However, it should be noted that our recent studies establish that the identity of the protein recognized by the anti-PKC $\zeta$ antiserum (which is known to cross-react with other aPKC isoforms [22, 23]) is $\mathrm{PKC} \lambda$ (3). The monoclonal anti-PKC $\alpha$ antibody was used at a 1:500 dilution in $1 \%$ bovine serum albumin, $50 \mathrm{mM}$ Tris- $\mathrm{HCl}, \mathrm{pH} 7.5$, $200 \mathrm{mM} \mathrm{NaCl}$, and $0.02 \% \mathrm{NaN}_{3}$ overnight at $4^{\circ} \mathrm{C}$. The polyclonal antisera were used at a 1:500 dilution in $3 \%$ bovine serum albumin, 50 $\mathrm{mM}$ Tris, $\mathrm{pH} 7.5,200 \mathrm{mM} \mathrm{NaCl}, 0.1 \%$ Triton-X 100, and $0.02 \% \mathrm{NaN}_{3}$ overnight at $4{ }^{\circ} \mathrm{C}$. The nitrocellulose was washed five times, $5 \mathrm{~min}$ each, with $50 \mathrm{mM}$ Tris, $\mathrm{pH} 7.5,200 \mathrm{mM} \mathrm{NaCl}, 2 \% \mathrm{NP}-40$, and incubated in the same buffer containing $5 \%$ dry milk (blocking buffer II) for 30 min at room temperature. To detect bound primary antibody, blots were incubated for $1 \mathrm{~h}$ at room temperature with ${ }^{125} \mathrm{I}$-labeled $\mathrm{F}\left(\mathrm{ab}^{\prime}\right)_{2}$ fragments of the second antibodies (goat anti-rabbit $\operatorname{IgG~F}\left(\mathrm{ab}^{\prime}\right)_{2}$ and sheep anti-mouse IgG $\mathrm{F}\left(\mathrm{ab}^{\prime}\right)_{2}$ fragments for polyclonal and monoclonal primary antibodies, respectively) at a final dilution of $0.25 \mu \mathrm{Ci} /$ $\mathrm{ml}$ in blocking buffer II. The nitrocellulose was washed seven times as described above, dried, and autoradiographed with X-AR film (Eastman Kodak Co., Rochester, NY) with intensifying screens at $-70^{\circ} \mathrm{C}$. The specificity of the immunoreactive proteins identified as PKC was established previously (4). The relative abundance of individual proteins identified was quantified using a PhosphorImager 445SI (Molecular Dynamics Inc., Sunnyvale, CA). Preliminary studies established that the radioactivity associated with each PKC isoform increased linearly with loading of increased amounts of sample protein.

Diacylglycerol assay. The lipid phase of a Bligh-Dyer extract was prepared as described previously (24) and the mass of DAG was assayed using a protocol which measures the quantitative conversion of DAG to phosphatidic acid catalyzed by the Escherichia coli DAG kinase enzyme (Amersham Corp., Arlington Heights, IL).

Materials. Polyclonal antibodies against $\mathrm{PKC} \delta$ and $\mathrm{PKC} \zeta$ were purchased from Gibco-BRL (Grand Island, NY) and the monoclonal antibody against $\mathrm{PKC} \alpha$ was purchased from Upstate Biotechnology Inc. (Lake Placid, NY). Polyclonal anti-PKC $\epsilon$ was the generous gift of Dr. Doriano Fabbro (Ciba Geigy, Basel, Switzerland) (25). ${ }^{125}$ I-labeled goat anti-rabbit $\operatorname{IgG~F}\left(\mathrm{ab}^{\prime}\right)_{2}$ fragment, ${ }^{125}$ I-labeled sheep anti-mouse $\operatorname{IgG~} \mathrm{F}\left(\mathrm{ab}^{\prime}\right)_{2}$ fragment, and $\left[\gamma^{-32} \mathrm{P}\right] \mathrm{ATP}(3,000 \mathrm{Ci} / \mathrm{mmol})$ were purchased from DuPont NEN (Boston, MA). PMA was purchased from Sigma Chemical Co. (St. Louis, MO). All other chemicals were reagent grade.

Statistical analysis. Data are presented as mean \pm SEM. Statistical comparisons were made using Student's $t$ test for paired observations or two-way ANOVA as indicated. Significance was defined at the $P<0.05$ level.

\section{Results}

Hypoxia induces specific alterations in the subcellular distribution of PKC isoforms. The first experiments were designed to determine whether hypoxia alters the subcellular distribution 

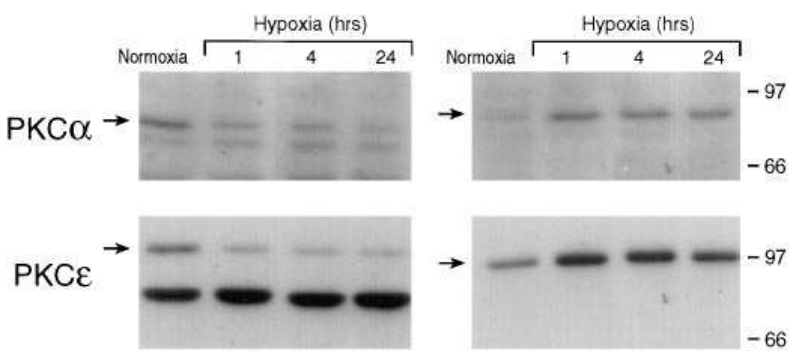

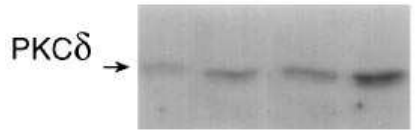

Soluble

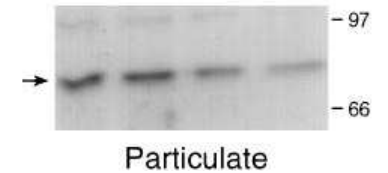

Particulate
Figure 1. Hypoxia alters the subcellular distribution of PKC isoforms. Soluble and particulate fractions were prepared from normoxic myocytes and myocytes subjected to hypoxia for the indicated time intervals. Fractions $(50 \mu \mathrm{g} / \mathrm{lane})$ were resolved by SDS-PAGE, transferred to nitrocellulose, and probed with the indicated antisera. The arrows identify specific immunoreactive bands representing PKC $\alpha$ (78 kD), PKC $\epsilon$ (96 kD), and PKC $\delta(73 \mathrm{kD})$. Data are from a single time course and are representative of results obtained in three separate culture preparations. Positions of the molecular mass standards (in kilodaltons) are indicated on the right.

of individual PKC isoforms. Our previous studies established that these cultures express PKC $\alpha, \mathrm{PKC} \delta, \mathrm{PKC} \epsilon$, and PKC $\lambda$. Accordingly, immunoblot analyses with antibodies that discriminate between these PKC isoforms were performed on soluble and particulate fractions of normoxic and hypoxic cultured neonatal rat ventricular myocytes.

Figs. 1 and 2 demonstrate that PKC $\alpha$ preferentially partitions to the soluble fraction of normoxic myocytes, whereas PKC $\delta$ and PKC $\epsilon$ associate with the particulate compartment of the cell even in the absence of PKC activators. Exposure to an hypoxic environment results in the translocation of $\mathrm{PKC} \alpha$ and PKC $\epsilon$ from the soluble to the particulate compartment of the cell. Fig. 1 shows that the hypoxia-induced redistribution of $\mathrm{PKC} \alpha$ and PKC $\epsilon$ is fully evident by $1 \mathrm{~h}$ and is persistent for at least 24 h; Fig. 2 shows that the effect is reversible within the first hour of reoxygenation. While $\mathrm{pO}_{2}$ falls rapidly and progressively when cultures are placed in the hypoxia chamber, profound hypoxia is established only between $0.5-1 \mathrm{~h}$ in the chamber. This argues that the hypoxia-induced translocation of PKC $\alpha$ and PKC $\epsilon$ is likely to be induced by relatively short intervals of profound hypoxia or at lower levels of oxygen deprivation.

Hypoxia exerts a different effect on PKC 8 . This PKC isoform preferentially partitions to the particulate fraction of normoxic cells. Hypoxia results in the redistribution of PKC $\delta$ to the soluble fraction (Fig. 1). The effect of hypoxia to decrease the membrane association of PKC $\delta$ is detectable in most experiments by $1 \mathrm{~h}$ of hypoxia. However, this represents a submaximal response as progressive redistribution to the soluble fraction occurs for at least another $23 \mathrm{~h}$. Moreover, while the hypoxia-induced redistribution of $\mathrm{PKC} \delta$ is reversible with reoxygenation, the return of PKC $\delta$ immunoreactivity to the particulate fraction occurs following a lag of several hours (Fig. 2). Thus, the kinetics of the hypoxia/reoxygenation-induced alterations in the subcellular distribution of PKC $\alpha / \mathrm{PKC} \epsilon$ (to the

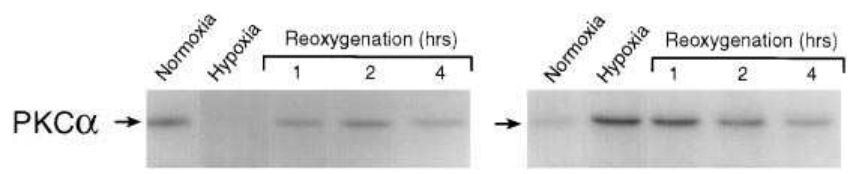

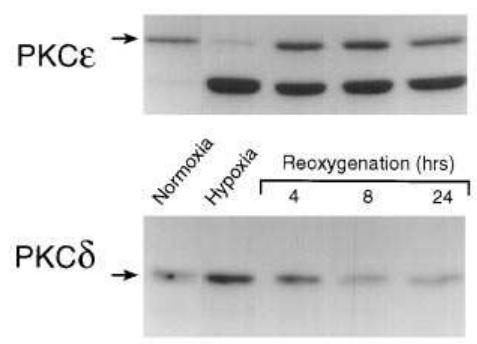

Soluble
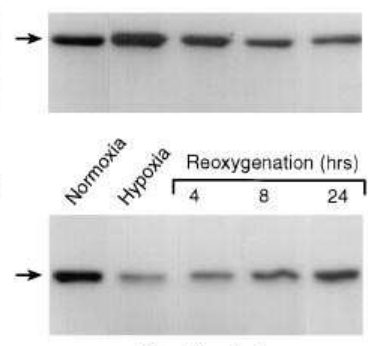

Particulate
Figure 2. The hypoxia-dependent redistribution of PKC isoforms reverses with reoxygenation. Soluble and particulate fractions were prepared from normoxic myocytes, myocytes subjected to hypoxia for $24 \mathrm{~h}$, and myocytes subjected to hypoxia for $24 \mathrm{~h}$ followed by reoxygenation for the indicated time intervals. Fractions $(50 \mu \mathrm{g} / \mathrm{lane})$ were resolved by SDS-PAGE, transferred to nitrocellulose, and probed with the indicated antisera. The arrows identify specific immunoreactive bands representing $\mathrm{PKC} \alpha$, the $96-\mathrm{kD}$ species of $\mathrm{PKC} \epsilon$, and PKC $\delta$. It should be noted that hypoxia also increases the abundance of a smaller soluble $76-\mathrm{kD}$ protein which is specifically recognized by the PKC $\epsilon$-specific antiserum (it is blocked by preincubation of the antiserum with peptide antigen, see Fig. 1 of reference 4). As previously reported, this immunoreactive species resides exclusively in the soluble compartment and does not undergo translocation or down-regulation in response to PMA (4). The magnitude of the hypoxia-induced increase in the abundance of the 76-kD PKC $\epsilon$ immunoreactive species is quite variable; The effect is modest in cultures that contain ample immunoreactivity in normoxia (see Fig. 1), whereas it is quite pronounced in cultures that express low levels of this immunoreactive species in normoxia (see this figure). Separate studies indicate that the considerable culture-dependent variability in the expression of this PKC€ immunoreactive species can be attributed, at least in part, to serum components in the culture medium and that this protein is devoid of protein kinase C enzyme activity (data not shown). The physiologic significance of the regulated expression of this protein in cardiac myocytes currently is uncertain. Data are from a single experiment and are representative of results obtained in three separate culture preparations.

particulate fraction) and $\mathrm{PKC} \delta$ (to the soluble fraction) are quite distinct, suggesting that these events are mediated by distinct mechanisms.

The results of a series of separate experiments are quantified in Fig. 3. Hypoxia significantly decreases the abundance of PKC $\alpha$ and PKC $\epsilon$ in the soluble fraction, while it increases the abundance of PKC $\delta$ in the soluble fraction. It should be noted that for each PKC isoform, changes in immunoreactivity in the soluble fraction were balanced by reciprocal changes in immunoreactivity in the particulate fraction. This suggests that hypoxia induces the subcellular redistribution of PKC isoforms, rather than a change in their abundance. However, there is evidence that the calcium-dependent proteases $\mu$ - and $m$-calpain are activated as a result of calcium influx during ischemia and reperfusion (26). Since cPKC and $\mathrm{nPKC}$ isoforms are in vitro substrates for calpain-dependent proteolysis (27), we examined whether hypoxia results in the formation of smaller catalytic fragments of PKC. In separate immunoblotting experiments, the entire molecular weight range of proteins 


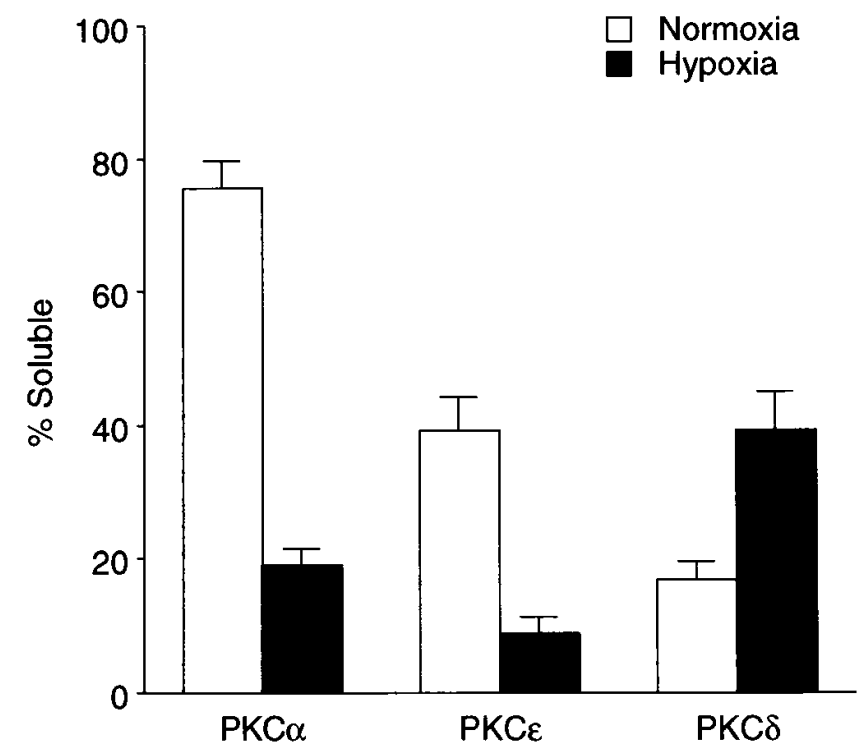

Figure 3. Quantitation of the hypoxia-induced redistribution of PKC isoforms. Immunoblot analysis on soluble and particulate fractions of normoxic myocytes and myocytes exposed to hypoxia for $24 \mathrm{~h}$ were quantified using a PhosphorImager. Calculations of the amount of each $\mathrm{PKC}$ isoform that resides in the soluble and particulate fractions take into account the twofold greater recovery of protein in the particulate fraction than in the soluble fraction. PKC isoform immunoreactivity that partitions to the soluble fraction is expressed as the percentage of the calculated total PKC isoform immunoreactivity in each preparation (which did not differ between normoxic and hypoxic cultures). Data represent the mean \pm SEM from 14 experiments on separate culture preparations. For each PKC isoform, the hypoxiainduced redistribution was highly significant $(P<0.0001$ for $\mathrm{PKC} \alpha$ and $\mathrm{PKC} \delta ; P<0.005$ for $\mathrm{PKC} \delta$ ).

was probed for individual $\mathrm{PKC}$ isoform immunoreactivity. No catalytic fragments of PKC were detected in the hypoxic samples (data not shown). Moreover, separate experiments on whole cell extracts from normoxic and hypoxic myocytes demonstrated that hypoxia does not detectably alter the abundance of any PKC isoform (data not shown). Thus, redistribution appears to completely account for the observed changes in PKC isoform abundance in the soluble and particulate compartments. Separate experiments also established that hypoxia does not influence the subcellular distribution or the abundance of PKC $\lambda$ (data not shown).

$P K C$ isoform activation in hypoxic myocytes. Given the observation that hypoxia leads to a decrease in the membrane association of PKC\&, we next considered the possibility that the intracellular structure(s) required for PKC $\delta$ binding is so disrupted by hypoxia, that phorbol ester-induced translocation to the particulate fraction is no longer possible. Fig. 4 shows that this is not the case. Incubation with PMA results in the rapid and complete translocation of $\mathrm{PKC} \delta$ to the particulate fraction. A short exposure to PMA results in the complete translocation of soluble PKC $\alpha$ and PKCe to the particulate compartment and prolonged stimulation with PMA leads to comparable complete (PKC $\alpha$ and PKC $\delta$ ) or substantial (PKC $\epsilon$ ) down-regulation of PKC in both normoxic and hypoxic myocytes. These results suggest that the hypoxia-induced redistribution of PKC isoforms does not lead to any gross changes in PMA-stimulated activation and/or down-regulation of PKC.
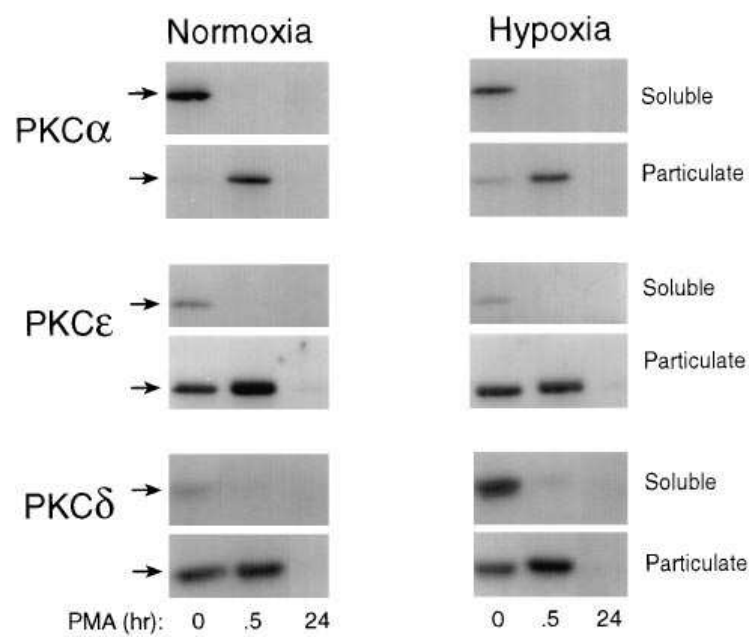

Figure 4. PMA-dependent activation of PKC in normoxic and hypoxic myocytes. Soluble and particulate fractions were prepared from myocytes that were cultured without PMA or with $1 \mu \mathrm{M}$ PMA for 30 min or $24 \mathrm{~h}$. In hypoxic myocytes, treatment with PMA occurred during the entire or the final $30 \mathrm{~min}$ of the 24-h hypoxic exposure. Samples $(40 \mu \mathrm{g} / \mathrm{lane})$ were subjected to SDS-PAGE, transferred to nitrocellulose, and probed with the indicated antisera as described in Methods. Arrows identify specific PKC immunoreactivity. Results are from a single experiment and are representative of data from three separate culture preparations.

The role of phospholipase $C$ and calcium in the hypoxiainduced translocation of PKC isoforms. An effect of hypoxia to induce the translocation of PKC could be due to an hypoxia-induced increase in intracellular DAG. Indeed, the hypoxic stress used in this study leads to a $46 \%$ increase in the concentration of DAG (from $86.7 \pm 6.3$ to $126.7 \pm 5.0 \mathrm{pmol} /$ 35 -mm dish, $n=8, P<0.05)$. To determine whether the activation of phospholipase $\mathrm{C}$ and the generation of DAG underlies the hypoxia-induced redistribution of $\mathrm{PKC}$ isoforms, we used the antiviral and antitumoral xanthate compound tricyclodecan-9-yl-xanthogenate (D609). This drug inhibits phosphatidylcholine-specific phospholipase $\mathrm{C}$ in in vitro and in vivo assay systems $(28,29)$. While D609 reportedly does not inhibit the activity of purified phosphatidylinositol-4,5-bisphosphatespecific phospholipase $\mathrm{C}$ in an in vitro assay system (under conditions where phosphatidylcholine-specific phospholipase $\mathrm{C}$ is inhibited [29]), we and others have shown that D609 inhibits agonist- or stretch-dependent activation of phosphatidylinositol-specific phospholipase $\mathrm{C}$ in vivo in neonatal rat ventricular myocytes $(30,31)$. D609 completely blocks the hypoxia-induced increase in DAG $(85.1 \pm 3.2 \mathrm{pmol} / 35-\mathrm{mm}$ dish $)$. While D609 does not alter the subcellular distribution of PKC $\alpha$ and PKC $\epsilon$ in normoxic myocytes, it blocks the translocation of PKC $\alpha$ and $\mathrm{PKC} \epsilon$ to the particulate fraction in hypoxic myocytes (Fig. 5). The further observation that D609 does not prevent PMAdependent translocation of PKC $\alpha$ and PKC $\epsilon$ to the particulate fraction (data not shown) argues that inhibition of the hypoxia-induced translocation of PKC by D609 is specific, and not due to a nonspecific toxic effect of the drug. D609 does not influence the subcellular distribution of PKC $\delta$ in normoxic myocytes and does not prevent the redistribution of PKC $\delta$ to the soluble fraction in hypoxic myocytes (data not shown).

We next considered the possibility that the hypoxia-induced 


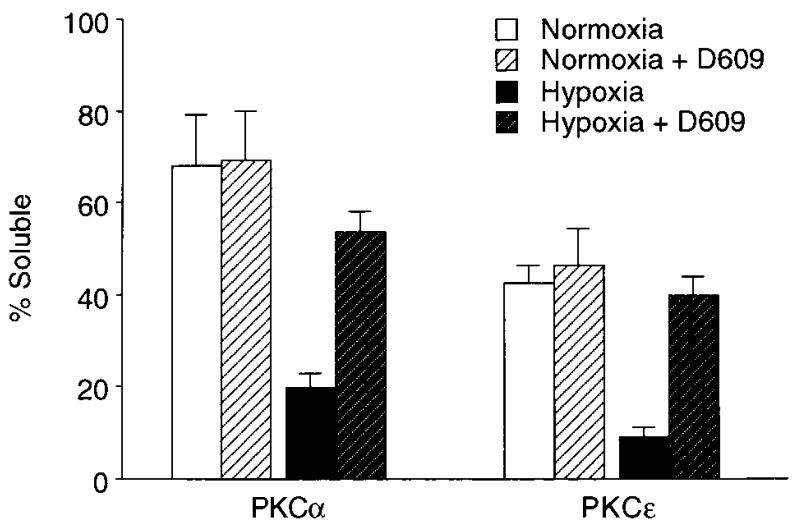

Figure 5. D609 inhibits the hypoxia-dependent redistribution of PKC $\alpha$ and PKC $\epsilon$. Myocytes grown for $4 \mathrm{~d}$ in a normoxic incubator, preincubated for $12 \mathrm{~h}$ with vehicle or D609 $(100 \mu \mathrm{M})$ in the normoxic environment, and then maintained in the normoxic incubator or transferred to the hypoxia chamber for an additional $4 \mathrm{~h}$ in the absence or continued presence of D609. Soluble and particulate fractions were prepared, subjected to SDS-PAGE, transferred to nitrocellulose, and probed with the anti-PKC isoform specific antisera as described in Methods. The results represent the mean \pm SEM for data from three determinations from separate culture preparations. Hypoxia resulted in a significant decrease in PKC $\alpha$ and PKC $\epsilon$ in the soluble fraction $(P<0.05)$. D609 did not alter the subcellular distribution of PKC $\alpha$ and PKC $\epsilon$ in normoxia. For both PKC $\alpha$ and PKC $\epsilon$, D609 blocked the hypoxia induced fall in immunoreactivity in the soluble fraction $(P<0.05)$.

redistribution of $\mathrm{PKC}$ isoforms may result from changes in intracellular calcium. To determine whether PKC isoforms redistribute as a result of a calcium-dependent pathway, cells were incubated with the membrane permeable acetoxymethyl

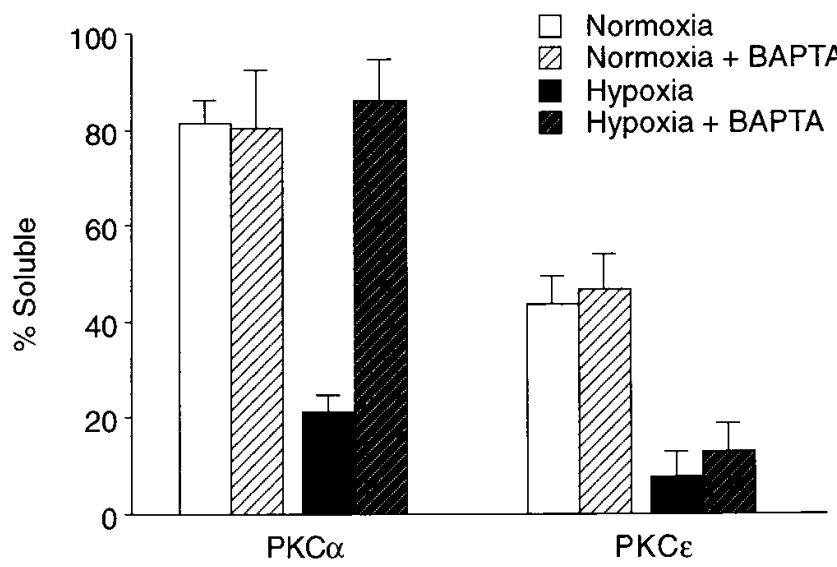

Figure 6. The effect of BAPTA on the subcellular distribution of PKC $\alpha$ and PKC $\epsilon$. Myocytes grown for $4 \mathrm{~d}$ in a normoxic environment were exposed to BAPTA/AM $(25 \mu \mathrm{M})$ or vehicle for $30 \mathrm{~min}$, washed to remove residual extracellular BAPTA/AM, and then placed in the hypoxia chamber or a normoxic incubator for $4 \mathrm{~h}$. Soluble and particulate fractions were prepared, subjected to SDS-PAGE, transferred to nitrocellulose, and probed with the anti-PKC isoform specific antisera as described in Methods. The results represent the mean \pm SEM for data from four determinations from separate culture preparations. Hypoxia resulted in a significant decrease in PKC $\alpha$ and PKC $\epsilon$ in the soluble fraction $(P<0.05)$. BAPTA did not alter the subcellular distribution of PKC $\alpha$ and PKC $\epsilon$ in normoxia. BAPTA completely blocked the hypoxia induced fall in PKC $\alpha$ (but not PKC $\epsilon$ ) in the soluble fraction $(P<0.05)$. ester of the calcium-chelating compound 1,2-bis(2-aminophenoxy)ethane- $N, N, N^{\prime}, N^{\prime}$ - tetraacetic acid (BAPTA/AM) for 30 min and washed free of residual extracellular BAPTA/AM before the hypoxic challenge. Preliminary experiments using quantitative fluorescence microscopy with fura- 2 established that this protocol effectively chelates intracellular calcium during the subsequent $4 \mathrm{~h}$ (as evidenced by the absence of detectable calcium transients during electrical field stimulation and the loss of a $\beta$-adrenergic receptor-dependent rise in intracellular calcium, data not shown). BAPTA does not alter the subcellular distribution of PKC $\alpha$ and PKCe in normoxic myocytes, but completely blocks the hypoxia-induced translocation of PKC $\alpha$ to the particulate fraction in hypoxic myocytes (Fig. 6). In contrast, the effect of hypoxia to translocate PKC $\epsilon$ to the particulate fraction persists in BAPTA-treated myocytes. BAPTA does not influence the subcellular distribution of PKC $\delta$ either in normoxic or hypoxic myocytes (data not shown).

Taken together, these results are most consistent with the conclusion that the hypoxia-dependent pathway for activation of PKC $\alpha$ is critically dependent upon the formation of DAG as well as a rise in intracellular calcium. In contrast, the pathway for activation of PKC $\epsilon$ is dependent upon the formation of DAG, but does not require a rise in intracellular calcium. Finally, the hypoxia-induced translocation of PKCS to the soluble fraction is mediated by a separate mechanism that does not involve DAG or calcium.

\section{Discussion}

$\mathrm{PKC}$ is increasingly recognized as a key regulatory enzyme in normal cardiac physiology. PKC may also play a pivotal role in the functional adaptation to myocardial ischemia and/or ischemic preconditioning. Despite the growing evidence that PKC becomes activated during myocardial ischemia, this is the first report to examine the effects of hypoxia on individual $\mathrm{PKC}$ isoforms in cardiac myocytes. This study establishes that the hypoxic component of an ischemic insult is sufficient to influence PKC.

Results reported herein establish that hypoxia leads to the translocation of PKC $\alpha$ and PKC $\epsilon$ to the particulate fraction. A similar effect of ischemia to induce the translocation of the calcium-sensitive PKC $\beta$ and PKC $\gamma$ isoforms from the cytosol to the membrane previously was reported in brain (32). Assuming that translocation to the membrane is an essential prerequisite for $\mathrm{PKC}$ isoform activation, studies reported herein suggest that hypoxia leads to the activation of PKC $\alpha$ and PKC $\epsilon$. Experiments with D609 and BAPTA indicate that the rise in DAG mediates the hypoxia-induced translocation/activation of PKC $\epsilon$, whereas the mechanism for the hypoxia-induced translocation/activation of PKC $\alpha$ involves a rise in DAG in association with perturbations in intracellular calcium. Whether hypoxia directly modulates the function of signal transducing molecules (receptors, G proteins, phospholipases, etc.) or leads to the release of soluble factors (angiotensin II, endothelin [33, 34]) that act on receptors to stimulate intracellular signal transduction pathways was not examined in our study. However, the evidence that activation of phosphoinositide hydrolysis by $\mathrm{G}$ protein-coupled receptors (including those that elicit large increases in intracellular calcium $[35,36])$ leads to a pattern of $\mathrm{PKC}$ redistribution that is quite distinct from that observed in our experiments (i.e., an increase in the membrane-association 
of PKC $\epsilon$ and PKC $\delta$, but no detectable redistribution of PKC $\alpha$ to the membrane fraction [5]) suggests that the receptordependent pathways defined in normoxic myocytes cannot entirely explain the hypoxia-induced translocations of PKC identified in this study. In this context, it is noteworthy that apart from the pharmacologic response to PMA, there is no precedent for the translocation/activation of PKC $\alpha$ in cardiac myocytes $(5,37)$. The observation reported herein that hypoxia induces the translocation of PKC $\alpha$ to the membrane compartment should provide the basis for future investigations into the mode of activation of PKC $\alpha$ in cardiac myocytes.

Another major finding of this study is that hypoxia leads to the redistribution of PKC $\delta$ to the soluble compartment. This result is surprising given the evidence that hypoxia translocates PKC $\epsilon$ to the particulate fraction via a DAG-dependent pathway; one would have anticipated that hypoxia also would recruit PKC $\delta$ to the membrane fraction. However, recent studies have uncovered a previously unrecognized level of complexity to the interaction of $\mathrm{PKC}$ isoforms with intracellular target structures which could suggest mechanisms to account for the hypoxia-induced translocation of PKC 8 . First, there is recent evidence that protein-protein interactions of PKC with anchoring proteins may stabilize the phospholipid-dependent translocation of PKC isoforms to membranes and/or play a role in targeting PKC to specific intracellular loci (38). Indeed, several intracellular PKC binding proteins with properties that conform to intracellular receptors for activated $\underline{\mathrm{C}}$-kinase (RACKs) have been identified in the triton-soluble fraction of rat heart and brain $(38,39)$. Other cytoskeletal-associated proteins, which are structurally distinct from RACKs, also have been reported to bind $\mathrm{PKC}$ in vitro and may confer additional anchoring sites for PKC in vivo (40). Thus, hypoxia-induced alterations in the subcellular distribution of PKC $\delta$ could be the result of changes in the expression or function of critical intracellular PKC binding proteins. Alternatively, it is possible that the in vivo subcellular location of PKC $\delta$ is not altered by hypoxia, but the nature of the interaction of PKC $\delta$ with the membrane structure is altered (perhaps as a result of hypoxia-induced changes in lipid cofactors that support stable PKC binding) such that PKC 8 becomes more susceptible to dissociation from the membrane during sample preparation (40). Future studies to explore these mechanisms are warranted.

Although hypoxia disrupts the membrane association of PKC $\delta$, biochemical subfractionation studies argue that PMAdependent recruitment of PKC $\delta$ to the membrane proceeds normally in hypoxic myocytes. Nevertheless, there may be subtle differences in the subcellular distribution of PKC $\delta$, which might escape detection using this technique. For example, we cannot exclude the possibility that PKC $\delta$ is associated with distinct structures in the particulate fractions of agoniststimulated normoxic and hypoxic myocytes, thereby influencing the phosphorylation and activation of substrates. Only immunocytochemical studies can reveal the precise intracellular topography of PKC and determine whether hypoxia alters the subcellular targeting of PKC $\delta$. Such differences would be important since they would, at least in theory, influence substrate accessibility and lead to changes in PKC-dependent function.

There is only limited previously published information on the effects of hypoxia/ischemia on the subcellular redistribution of PKC in cardiac tissue. Strasser et al. reported that acute ischemia results in the translocation of $\mathrm{PKC}$ from the soluble to the particulate fraction of adult rat ventricular myocardium (18). However, this study assayed PKC as histone-kinase activity and would only detect hypoxia-induced changes in $\mathrm{cPKC}$ isoforms (since histone is a good substrate for cPKC isoforms but is a relatively poor substrate for $\mathrm{nPKC}$ isoforms). In a more recent study, these investigators used immunoblot analysis to demonstrate that more prolonged ischemic intervals (30$60 \mathrm{~min}$ ) lead to the induction of PKC $\delta$ and PKC $\epsilon$ in the soluble fraction (19). In contrast, Webster et al. used a culture model similar to that employed in our study and demonstrated that hypoxia (for up to $8 \mathrm{~h}$ ) does not influence the subcellular distribution of PKC (41). The different results between the two studies on cultured neonatal rat ventricular myocytes can be reconciled on the basis of the distinct methods used to assess PKC. The prior study measured PKC enzyme activity with an EGF receptor peptide as substrate and would not discriminate hypoxia-induced changes in individual PKC isoforms. In contrast, our study used immunoblotting with PKC isoform specific antisera, which is capable of distinguishing changes in individual PKC isoforms, particularly under conditions where hypoxia simultaneously induces reciprocal changes in the abundance of individual PKC isoforms within a single cell compartment.

Given that translocation of PKC isoforms from the soluble to particulate compartment has been taken as the hallmark of PKC activation, presumably representing a mechanism to promote access to substrate, results reported herein suggests that hypoxia activates PKC $\alpha$ and PKC $\epsilon$. The functional consequences of $\mathrm{PKC} \alpha$ and PKC $\epsilon$ activation in cardiac myocytes remain uncertain. However, there is evidence that PKC $\alpha$ can directly activate Raf-1 (42) and thereby initiate a protein phosphorylation cascade that leads to changes in gene expression characteristic of the cardiac hypertrophic response (43). A similar linkage between PKC€ and Raf-1 kinase has been demonstrated in rodent fibroblasts and atrial cardiomyocytes $(36,44)$. Thus, the recent observation that hypoxia increases Raf-1 kinase activity which in turn activates downstream kinases including mitogen-activated protein kinase kinase (MEK), mitogen-activated protein kinase (MAPK), and S6 kinase (45) could be attributed to the hypoxia-dependent activation of $\mathrm{PKC} \alpha$ and/or PKC $\epsilon$ identified in this study. Whether activation of the MAPK cascade, in turn, is the mechanism underlying the effect of hypoxia to induce fos and jun and whether this directly elicits changes in the expression of other genes which promote hypertrophy and/or induce adaptive responses to hypoxia requires further study (41). Apart from its potential role in the control of myocyte growth, PKC $\epsilon$ has been implicated in the modulation of spontaneous contractile activity in cultured neonatal ventricular myocytes (46) and the regulation of intracellular calcium homeostasis in atrial cardiomyocytes (36). Thus, activation of PKC $\alpha$ and/or PKC $\epsilon$ during cardiac hypoxia/ischemia also could lead to the phosphorylation of substrates which contribute to the genesis of arrhythmias (47), influence myocardial contractile performance (48), and/or play a role in ischemic preconditioning (49-52).

\section{Acknowledgments}

This work was supported by U.S.P.H.S.-N.H.L.B.I. grants HL-49537 (S.F. Steinberg), a National Institutes of Health postdoctoral training grant in pharmacological sciences (grant 07271 to M. Goldberg). 


\section{References}

1. Nishizuka, Y. 1992. Intracellular signaling by hydrolysis of phospholipids and activation of protein kinase C. Science (Wash. DC). 258:607-614.

2. Steinberg, S.F., M. Goldberg, and V.O. Rybin. 1995. Protein kinase C isoform diversity in the heart. J. Mol. Cell. Cardiol. 27:141-153.

3. Rybin, V.O., P.M. Buttrick, and S.F. Steinberg. 1996. Protein kinase C-lambda is the atypical isoform expressed by the immature ventricle. Am. J. Physiol. In press.

4. Rybin, V.O. and S.F. Steinberg. 1994. Protein kinase C isoform expression and regulation in the developing rat heart. Circ. Res. 74:299-309.

5. Pucéat, M., R. Hilal-Dandan, B. Strulovici, L.L. Brunton, and J.H. Brown. 1994. Differential regulation of protein kinase C isoforms in isolated neonatal and adult cardiomyocytes. J. Biol. Chem. 269:16938-16944.

6. Disatnik, M.H., G. Buraggi, and D. Mochly-Rosen. 1994. Localization of protein kinase C isozymes in cardiac myocytes. Exp. Cell Res. 210:287-297.

7. Mochly-Rosen, D., C.J. Henrich, L. Cheever, H. Khaner, and P.C. Simpson. 1990. A protein kinase C isozyme is translocated to cytoskeletal elements on activation. Cell Regul. 1:693-706.

8. Church, D.J., S. Braconi, M.B. Vallotton, and U. Lang. 1993. Protein kinase C-mediated phospholipase A2 activation, platelet-activating factor generation and prostacyclin release in spontaneously beating rat cardiomyocytes. Biochem. J. 290:477-482.

9. Clerk, A., M.A. Bogoyevitch, S.J. Fuller, A. Lazou, P.J. Parker, and P.H. Sugden. 1995. Expression of protein kinase $\mathrm{C}$ isoforms during cardiac ventricular development. Am. J. Physiol. 269:H1087-H1097.

10. Corr, P.B., J.A. Shayman, J.B. Kramer, and R.J. Kipnis. 1981. Increased $\alpha$-adrenergic receptors in ischemic cat myocardium. J. Clin. Invest. 67:12321236.

11. Heathers, G.P., K.A. Yamada, E.M. Kanter, and P.B. Corr. 1987. Longchain acylcarnitines mediate the hypoxia-induced increase in alpha $a_{1}$-adrenergic receptors on adult canine myocytes. Circ. Res. 61:735-746.

12. Maisel, A.S., H.J. Motulsky, M.G. Ziegler, and P.A. Insel. 1987. Ischemia- and agonist-induced changes in alpha- and beta-adrenergic receptor traffic in guinea pig hearts. Am. J. Physiol. 253:H1159-H1166.

13. Butterfield, M.C. and R. Chess-Williams. 1990. Enhanced $\alpha$-adrenoceptor responsiveness and receptor number during global ischaemia in the Langendorf perfused rat heart. Br. J. Pharmacol. 100:641-645.

14. Dillon, J.S., X.H. Gu, and W.G. Nayler. 1988. Alpha ${ }_{1}$-adrenoceptors in the ischaemic and reperfused myocardium. J. Mol. Cell. Cardiol. 20:725-735.

15. Heathers, G.P., A.S. Evers, and P.B. Corr. 1989. Enhanced inositol trisphosphate response to alpha ${ }_{1}$-adrenergic stimulation in hypoxic cardiac myocytes. J. Clin. Invest. 83:1409-1413.

16. Steinberg, S.F., and A. Alter. 1993. Enhanced receptor-dependent inositol phosphate accumulation in hypoxic myocytes. Am. J. Physiol. 265:H691H699.

17. Kawana, S., H. Kimura, A. Miyamoto, H. Ohshika, and A. Namiki. 1993. $\alpha_{1}$-Adrenoceptors in neonatal rat cardiac myocytes: hypoxia alters the responsiveness of $\alpha_{1 \mathrm{~A}}$ and $\alpha_{1 \mathrm{~B}}$ subtypes. Life Sci. 53:411-416.

18. Strasser, R.H., R. Braun-Dullaeus, H. Walendzik, and R. Marquetant. 1992. $\alpha_{1}$-receptor-independent activation of protein kinase $\mathrm{C}$ in acute myocardial ischemia: mechanisms for sensitization of the adenylyl cyclase system. Circ. Res. 70:1304-1312.

19. Weinbrenner, C.E., G. Simonis, R. Marquetant, and R.H. Strasser. 1993. Selective regulation of calcium-dependent and calcium-independent subtypes of protein kinase $\mathrm{C}$ in acute and prolonged myocardial ischemia. Circulation. 88:I-101a. (Abstr.)

20. Zhang, J., R.B. Robinson, and S.A. Siegelbaum. 1992. Sympathetic neurons mediate developmental changes in cardiac sodium channel gating through long-term neurotransmitter action. Neuron. 9:97-103.

21. Steinberg, S.F., R.B. Robinson, H.B. Lieberman, D.M. Stern, and M.R. Rosen. 1991. Thrombin modulates phosphoinositide metabolism, cytosolic calcium, and impulse initiation in the heart. Circ. Res. 68:1216-1229.

22. Akimoto, K., K. Mizuno, S.I. Osada, S.I. Hirai, S.I. Tanuma, K. Suzuki, and S. Ohno. 1994. A new member of the third class in the protein kinase C family, PKC $\lambda$, expressed dominantly in an undifferentiated mouse embryonal carcinoma cell line and also in many tissues and cells. J. Biol. Chem. 269:1267712683.

23. Selbie, L.A., C. Schmitz-Peiffer, Y. Sheng, and T.J. Biden. 1993. Molecular cloning and characterization of $\mathrm{PKCl}$, an atypical isoform of protein kinase C derived from insulin-secreting cells. J. Biol. Chem. 268:24296-24302.

24. Steinberg, S.F., L.M. Kaplan, T. Inouye, J.F. Zhang, and R.B. Robinson. 1989. Alpha ${ }_{1}$-adrenergic stimulation of 1,4,5-inositol trisphosphate formation in rat ventricular myocytes. J. Pharmacol. Exp. Ther. 250:1141-1148.

25. Guadagno, S.N., C. Borner, and I.B. Weinstein. 1992. Altered regulation of a major substrate of protein kinase $\mathrm{C}$ in rat 6 fibroblasts overproducing PKC-B1. J. Biol. Chem. 267:2697-2707.

26. Yoshida, K.I., Y. Tamasaki, and S.I. Kawashima. 1993. Calpain activity alters in rat myocardial subfractions after ischemia or reperfusion. Biochem. Biophys. Acta. 1182:215-220.
27. Saido, T.C., K. Mizuno, Y. Konno, S. Osada, S. Ohno, and K. Suzuki. 1992. Purification and characterization of protein kinase C epsilon from rabbit brain. Biochemistry. 31:482-490.

28. Muller-Decker, K. 1989. Interruption of TPA-induced signals by an antiviral and antitumoral xanthate compound: inhibition of a phospholipase C-type reaction. Biochem. Biophys. Res. Commun. 162:198-205.

29. Schutze, S., K. Potthoff, T. Machleidt, D. Berkovic, K. Wiegmann, and M. Kronke. 1992. TNF activates NF-кB by phosphatidylcholine-specific phospholipase C-induced "acidic" sphingomyelin breakdown. Cell. 71:765-776.

30. Jiang, T., V. Kuznetsov, E. Pak, H.L. Zhang, R.B. Robinson, and S.F. Steinberg. 1996. Thrombin receptor actions in neonatal rat ventricular myocytes. Circ. Res. 78:553-563.

31. Sadoshima, J., and S. Izumo. 1993. Mechanical stretch rapidly activates multiple signal transduction pathways in cardiac myocytes: potential involvement of an autocrine/paracrine mechanism. EMBO (Eur Mol. Biol. Organ.) J. 12:1681-1692

32. Wieloch, T., M. Cardell, H. Bingren, J. Zivin, and T. Saitoh. 1991 Changes in the activity of protein kinase $\mathrm{C}$ and the differential subcellular redistribution of its isozymes in the rat striatum during and following transient forebrain ischemia. J. Neurochem. 56:1227-1235.

33. Sadoshima, J., Y. Xu, H.S. Slayter, and S. Izumo. 1993. Autocrine release of angiotensin II mediates strech-induced hypertrophy of cardiac myocytes in vitro. Cell. 75:977-984

34. Yamazaki, T., I. Komuro, S. Kudoh, Y. Zou, I. Shiojima, Y. Hiroi, T Mizuno, K. Maemura, H. Kurihara, R. Aikawa, H. Takano, and Y. Yazaki. 1996. Endothelin-1 is involved in mechanical-stress-induced cardiomyocyte hypertrophy. J. Biol. Chem. 271:3221-3228.

35. Pucéat, M., O. Clement, F. Scamps, and G. Vassort. 1991. Extracellular ATP-induced acidification leads to cytosolic calcium transient rise in single rat cardiac myocytes. Biochem. J. 274:55-62.

36. Jiang, T., E. Pak, H.L. Zhang, R.P. Kline, and S.F. Steinberg. 1996. Endothelin-dependent actions in cultured AT-1 cardiac myocytes: The role of the $\epsilon$-isoform of protein kinase C. Circ. Res. 78:724-736.

37. Clerk, A., M.A. Bogoyevitch, M.B. Andersson, and P.H. Sugden. 1994. Differential activation of protein kinase $\mathrm{C}$ isoforms by endothelin-1 and phenylephrine and subsequent stimulation of p42 and p44 mitogen-activated protein kinases in ventricular myocytes cultured from neonatal rat hearts. J. Biol. Chem. 269:32848-32857.

38. Mochly-Rosen, D. 1995. Localization of protein kinases by anchoring proteins: a theme in signal transduction. Science (Wash. DC). 268:247-251.

39. Ron, D., C.H. Chen, J. Caldwell, L. Jamieson, E. Orr, and D. MochlyRosen. 1994. Cloning of an intracellular receptor for protein kinase C: A homolog of the $\beta$ subunit of G proteins. Proc. Natl. Acad. Sci. USA. 91:839-843.

40. Hyatt, S.L., L. Liao, C. Chapline, and S. Jaken. 1994. Identification and characterization of $\alpha$-protein kinase $\mathrm{C}$ binding proteins in normal and transformed REF52 cells. Biochemistry. 33:1223-1228.

41. Webster, K.A., D.J. Discher, and N.H. Bishopric. 1993. Induction and nuclear accumulation of Fos and Jun proto-oncogenes in hypoxic cardiac myocytes. J. Biol. Chem. 268:16852-16858.

42. Kolch, W., G. Heldecker, G. Kochs, R. Hummel, H. Vahldl, H. Mischak, G. Finkenzeller, D. Marme, and U.R. Rapp. 1993. Protein kinase C $\alpha$ activates RAF-1 by direct phosphorylation. Nature (Lond.). 364:249-252.

43. Goode, N., K. Hughes, J.R. Woodgett, and P.J. Parker. 1992. Differential regulation of glycogen synthase kinase- $3 \beta$ by protein kinase $\mathrm{C}$ isotypes. $J$. Biol. Chem. 267:16878-16882.

44. Cacace, A.M., S.N. Guadagno, R.S. Krauss, D. Fabbro, and I.B. Weinstein. 1994. The epsilon isoform of protein kinase $C$ is an oncogene when overexpressed in rat fibroblasts. Oncogene. 8:2095-2104.

45. Seko, Y., K. Tobe, K. Ueki, T. Kadowaki, and Y. Yazaki. 1996. Hypoxia and hypoxia/reoxygenation activate Raf-1, mitogen-activated protein kinase kinase, mitogen-activated protein kinases and S6 kinase in cultured rat cardiac myocytes. Circ. Res. 78:82-90.

46. Johnson, J.A. and D. Mochly-Rosen. 1995. Inhibition of the spontaneous rate of contraction of neonatal cardiac myocytes by protein kinase $\mathrm{C}$ isozymes: A putative role for the $\epsilon$ isozyme. Circ. Res. 76:654-663.

47. Priori, S.G., and P.B. Corr. 1990. The importance of $\alpha$-adrenergic stimulation of cardiac tissue and its contribution to arrhythmogenesis during ischemia. J. Cardiovasc. Electrophysiol. 1:529-542.

48. Noland, T.A., and J.F. Kuo. 1991. Protein kinase C phosphorylation of cardiac troponin I or troponin $\mathrm{T}$ inhibits $\mathrm{Ca}^{2+}$-stimulated actomyosin $\mathrm{MgAT}$ Pase activity. J. Biol. Chem. 266:4974-4976.

49. Lawson, C.S., and J. Downey. 1993. Preconditioning: state of the art myocardial protection. Cardiovas. Res. 27:542-550.

50. Mitchell, M.B., X. Meng, L. Ao, J.M. Brown, A.H. Harken, and A. Banerjee. 1995. Preconditioning of isolated rat heart is mediated by protein kinase C. Circ. Res. 76:73-81.

51. Speechly-Dick, M.E., M.M. Mocanu, and D.M. Yellon. 1994. Protein kinase C: its role in ischemic preconditioning in the rat. Circ. Res. 75:586-590.

52. Li, Y., and R.A. Kloner. 1995. Does protein kinase C play a role in ischemic preconditioning in rat hearts? Am. J. Physiol. 268:H426-H431. 